\title{
Fenfluramine and N-Ethyl Amphetamine: Comparison of the Reinforcing and Rate-Decreasing Actions in the Rhesus Monkey*
}

\author{
RICHARD E. TESSEL** and JAMES H. WOODS \\ Departments of Pharmacology and Psychology, The University of Michigan, Ann Arbor, Michigan
}

Received January 30, 1975; Final Version May 7, 1975

\begin{abstract}
N-ethyl amphetamine $\mathrm{HCl}$ (NEA) and fenfluramine $\mathrm{HCl}$ (meta-trifluoromethyl $\mathrm{N}$-ethyl amphetamine) were evaluated as reinforcers in rhesus monkeys that had been previously trained to press a lever using food presentations and cocaine $\mathrm{HCl}$ injections as reinforcers. Each daily session consisted of episodic opportunities to obtain reinforcers under a fixedratio schedule of 30 . A drug period was interpolated between two periods in which lever-press responding was maintained by food presentations. Compared to saline, none of the drugs altered the rate of responding in the food periods which preceded the drug sessions, indicating the absence of residual response-disrupting drug actions from previous ses-
\end{abstract}

sions. However, NEA and fenfluramine self-injection resulted in dose-related decreases in response rates during the food periods which immediately followed the drug sessions. Cocaine $\mathrm{HCl}(30 \mu \mathrm{g} / \mathrm{kg} /$ injection $)$ maintained high response rates at over one response/second during the drug periods, as did the same dose of NEA. Doses of 10 and $100 \mu \mathrm{g} / \mathrm{kg} /$ injection of NEA as well as all doses of fenfluramine $\mathrm{HCl}(10$ through $300 \mu \mathrm{g} / \mathrm{kg} /$ injection) maintained rates that were not different from those associated with saline injections. These results substantiate and extend earlier findings with fenfluramine and indicate that its failure to act as a reinforcer is attributable to its meta-trifluoromethyl group.

Key words: N-Ethyl Amphetamine - Fenfluramine - Cocaine - Self-Administration - Operant Conditioning - Rhesus Monkeys.

Fenfluramine (meta-trifluoromethyl N-ethyl amphetamine) is a pharmacological agent which, like amphetamine, is efficacious in the treatment of human obesity and can induce weight loss in animals (Le Douarec and Neveu, 1970; Woodward, 1970). However, in contrast to amphetamine, fenfluramine is not a stimulant of most measures of spontaneous locomotor activity in animals (Ziance et al., 1972; Tessel et al., $1975 \mathrm{~b}$ ) and is less potent and efficacious than amphetamine as a sympathomimetic agent (Bizzi et al., 1970; Babulova et al., 1972; Tessel et al., 1975a). In addition, fenfluramine has been found to be devoid of the capacity to reinforce drug-taking behavior in rhesus monkeys (Woods and Tessel, 1974) while amphetamine reinforces self-injection responding $(e . g$., Balster and Schuster, 1973).

Fenfluramine differs from amphetamine with respect to the presence of an ethyl group on the nitrogen and $\mathrm{CF}_{3}$ group at the meta position of the phenyl ring of the fenfluramine molecule. Thus the differences in pharmacological action between fenfluramine and

* Supported in part by USPHS Grant DA-00154.

** R.E.T. was an NIH Predoctoral Trainee in Pharmacology, USPHS Grant GM-00198. Present address: Department of Pharmacology, University of Colorado Medical School, Denver, Colorado 80220. amphetamine could be due to either or both structural variations. However, Tessel et al. $(1975 \mathrm{a}, \mathrm{b})$ have demonstrated that $\mathrm{N}$-ethyl amphetamine is potent and efficacious both as a sympathomimetic and as a stimulant of locomotor activity. Consequently, fenfluramine's relative lack of action in these preparations. is attributable to the $\mathrm{CF}_{3}$ group. The purpose of the present study was to determine whether the $\mathrm{CF}_{3}$ group was responsible as well for fenfluramine's ineffectiveness as a reinforcer (Woods and Tessel, 1974) by comparing the reinforcing efficacies of NEA and fenfluramine as reinforcers of self-injection responding in rhesus monkeys. An experimental situation was used in which behavioral actions other than the reinforcing effect of these drugs could be assessed sequentially in the same subject during a session.

\section{Methods}

Three experimentally naive rhesus monkeys (Macaca mulatta), weighing $4-6 \mathrm{~kg}$, were used in the experiment. Monkeys were deprived of food until they reached $80 \%$ of their ad libitum body weight and were maintained at $80 \%$ throughout the study. The animals were then removed daily from their individual home cages, placed in restraint chairs, and put into a sound-attenuating cubicle containing a response lever (model 121-07, Lehigh Valley Electronics, Fogelsville, Pa.) 
and various colored stimulus lights (model C7-CC, General Electric).

Initially, each lever press (response) in the presence of an illuminated red light resulted in the delivery of a $300-\mathrm{mg}$ banana-flavored food pellet (P. J. Noyes Co., Lancaster, N.H.) from a dispenser (model A, Ralph Gerbrands, Inc., Arlington, Mass.) located outside of the cubicle. Over several sessions, the response requirement was increased until 30 responses were required for reinforcement delivery. Another period, indicated by a green light, followed reinforcement or the failure to complete the response requirement within $1 \mathrm{~min}$. During this green-light period, each response delayed the onset of the next red-light period for a specified number of seconds and over the course of several sessions, the length of the green-light period was increased to $30 \mathrm{sec}$. Each response during this period delayed the onset of the next red-light period by $30 \mathrm{sec}$ as determined from that response.

When response rates had stabilized on this schedule, each monkey was implanted with a siliconized rubber catheter (Silatube; inner diameter $=0.031 \mathrm{in}$., outer diameter $=0.094$ in., Rodhelm Reiss Company, Belle Mead, N.J.) in either the right or left femoral vein or the right or left internal jugular vein. The distal end of the catheter was passed under the skin and exited from a stab wound in the midscapular area. A leather vest was fitted to each monkey to protect the catheter. Details of the animals' maintenance and surgical procedures have been reported previously (Deneau et al., 1969).

After food-reinforced response rates had returned to presurgical values, the animals were exposed to another schedule of reinforcement. Using the same procedure described above, the monkeys were allowed a maximum of 40 food reinforcements (Food Period I; FP I). After the termination of the last green-light period of FP I, a white-light period (Drug Period; DP) was initiated during which 30 responses were required for drug injection. A $15-\mathrm{sec}$, catheter-born injection of cocaine $\mathrm{HCl}(30 \mu \mathrm{g} / \mathrm{kg})$ was delivered in $0.50 \mathrm{ml}$ of $0.9 \%$ saline solution by a motor-driven syringe (model 249-2, Sage Instruments, Inc., White Plains, N.Y.). The white light was turned off and a blue light was illuminated during each injection. As in FP I, a 30-sec green-light period followed each reinforcement during the drug period. However, in contrast to FP I, responses during these green-light periods and during the injections had no programmed consequences. The drug period was terminated after $1 \mathrm{hr}$ or after the delivery of 40 injections, whichever occurred first. A second food period (FP II; identical in procedure to FP I) immediately followed the drug period.

After stable, high rates of responding were obtained from session to session using cocaine as the drug reinforcer, saline was substituted for cocaine and remained available for at least eight sessions. The animals were then offered cocaine again until response rates returned to presubstitution values (i.e. restabilization). Subsequently, doses of $d, 1-\mathrm{N}$-ethyl amphetamine $\mathrm{HCl}$ (NEA) were offered in an unsystematic sequence. Following the completion of the doses of NEA, several doses of $d, 1$-fenfluramine $\mathrm{HCl}$ were examined. Exposure to the various doses of the compounds was for at least eight consecutive sessions. Animals were restabilized on cocaine between the 2 drugs, after exposure to saline, and after exposure to drug doses which did not maintain responding at rates which were significantly higher than those associated with saline (i.e., were not reinforcing). Doses are expressed as the salts; $0.9 \%$ saline was used as the vehicle.

In view of the previous data indicating fenfluramine's lack of reinforcing efficacy (e.g., Woods and Tessel, 1974), it was important that saline-associated response rates be sufficiently low to allow demonstration of any small reinforcing action that might manifest itself with fenfluramine. Consequently, the animals were exposed to saline prior to starting the fenfluramine dose-response curve. One monkey was removed from the study at this point due to high salineassociated response rates. Thus observations on fenfluramine are based upon the remaining 2 monkeys.

Responses and reinforcements were recorded on digital counters and on a cumulative recorder. Timing and counting operations were automatically controlled and recorded. Response rates were computed by dividing the number of lever responses emitted during the red- and white-light periods by the times elapsed in those periods. The response rate measure thus excluded responses during the green-light periods and during injections. All averages and measures of variability are based upon the last three sessions of each series at a dose and they are combined across subjects. Differences between means were evaluated through the use of Student's $t$ for correlated means (Adkins, 1964).

\section{Results}

When cocaine $(30 \mu \mathrm{g} / \mathrm{kg} /$ injection) was available during the drug period, the average response rate during the first food period was $4.42 \pm 0.28$ responses $/ \mathrm{sec}$; during the drug period, it was $2.17 \pm 0.43$ responses/ sec (Fig. 1). The response rate during the second food period was $3.11 \pm 0.23$ responses/sec. The Food Period II rates were significantly depressed as compared to those in Food Period I $(P<0.01)$, presumably as a result of an average drug intake of $1.2 \mathrm{mg} / \mathrm{kg}$ of cocaine during the drug period (Fig. 2).

When saline was substituted for cocaine during DP, the response rate during Food Period I was not significantly altered, and the saline-associated rates for the 2 food periods were not different. The rate of responding during the drug period, however, dropped to a very low level $(0.16 \pm 0.04$ responses/ $\mathrm{sec}$.

Substitution of various doses of NEA during the subsequent drug periods had little effect on the rate of food-reinforced responding in Food Period I as compared to the FPI rates when saline was available during the DP (Fig. 1). Response rate during the drug period was an inverted $V$-shaped function of NEA dose: the maximal rate of $1.52 \pm 0.37$ responses $/ \mathrm{sec}$, which was significantly higher than saline control rate $(P<0.01)$, occurred at a dose of $30 \mu \mathrm{g} / \mathrm{kg} / \mathrm{in}-$ jection; the rates associated with the lower and higher doses (10 and $100 \mu \mathrm{g} / \mathrm{kg} /$ injection, respectively) did not differ from saline. The maximal rate for NEA did not differ from that which occurred when cocaine was the reinforcer. NEA intake was a monotonic increasing function of dose (Fig. 2). Food Period II rate following various doses of NEA self-injection was a decreasing function of dose (Fig. 1). The largest dose resulted in a statistically significant decrease in the Food Period II rate of responding compared to saline $(P<0.01)$. 


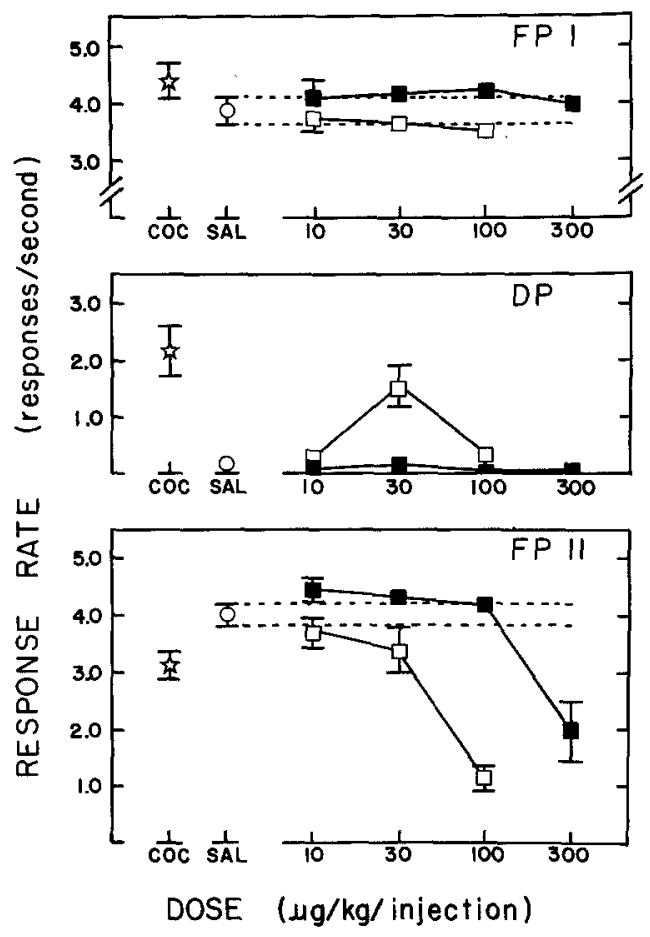

Fig. 1. Response rate as a function of dose for cocaine $\mathrm{HCl}$ $(30 \mu \mathrm{g} / \mathrm{kg} /$ injection; star), saline (circle), N-ethyl amphetamine $\mathrm{HCl}$ (NEA; open squares) and fenfluramine $\mathrm{HCl}$ (solid squares). The top panel corresponds to Food Period I, the middle panel to the Drug Period, and the bottom panel to Food Period II. Data points represent the means of the last three of at least eight sessions of exposure at each dose (or saline) and are comprised of rates of responding in the presence of the red light (FPI and FPII) and in the presence of the white light in the drug period. Vertical bars signify \pm S.E.M. $(N=6$, fenfluramine points; $N=9$, saline and NEA points)

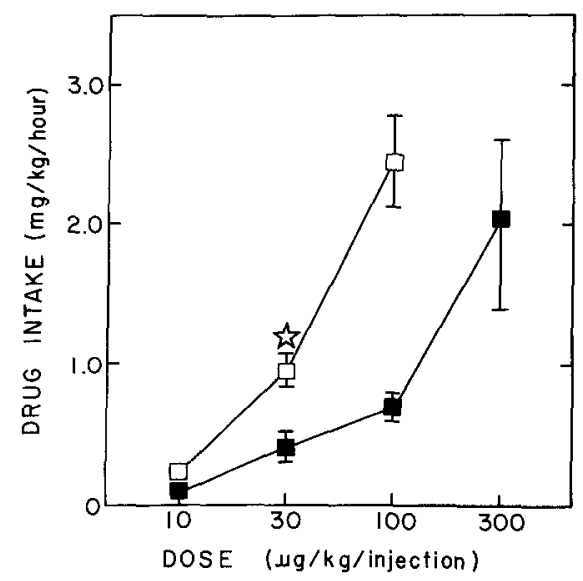

Fig. 2. Drug intake ( $\mathrm{mg} / \mathrm{kg} / \mathrm{session}$; ordinate) as a function of dose (abscissa) for cocaine $\mathrm{HCl}$ (star), N-ethyl amphetamine $\mathrm{HCl}$ (open squares) and fenfluramine $\mathrm{HCl}$ (solid sqaures). Points represent the means of the last three of at least eight sessions of exposure at each dose. Vertical lines represent \pm 1 S.E.M. Numbers of observations are the same as in legend of Fig. 1
The results with fenfluramine were similar to those just described for NEA except in the drug period. Doses of 10 through $300 \mu \mathrm{g} / \mathrm{kg} /$ injection of fenfluramine had little effect on responding in the first food period (Fig. 1). However, as with NEA, fenfluramine caused a significant decrease in Food Period II response rates that was associated with an increase in drug intake (Fig. 2).

Some examples showing the temporal distribution of lever-press responding are seen in Figs. 3 and 4 for the saline and drug conditions. In Food Period I of each individual record, responding was characterized by high, sustained rates during those portions in which food was available (i.e., red-light periods), followed by periods of little or no responding during portions in which each response delayed the onset of the next red-light period for $30 \mathrm{sec}$ (i.e., green-light periods). The response pattern is typical of this schedule of reinforcement (Woods and Tessel, 1974) and it is representative of the other monkeys in the present experiment.

During initial portions of the drug period when cocaine was used as the reinforcer (Fig. 3, top record), responding occurred at high rates during the drug period, during drug injections, and during green-light periods. Thus, frequent injections occurred. During later portions of the drug period, responding during injections and during the green-light periods ceased almost completely. High-rate green-light-period responding during the drug period did not occur in either of the other 2 monkeys, although they responded occasionally during injections.

NEA (Fig. 3; middle and lower records) at the dose of $30 \mu \mathrm{g} / \mathrm{kg}$ produced a pattern of drug-reinforced responding very similar to that of cocaine in this monkey. The other monkeys responded at lower rates. At the higher doses of $100 \mu \mathrm{g} / \mathrm{kg}$, responding to produce injections occurred rapidly at the beginning of the drug period and more slowly as it progressed. Similar amounts and patterns of responding are seen with saline and the $30 \mu \mathrm{g} / \mathrm{kg}$ dose of fenfluramine (Fig. 4; upper and middle records). The larger dose of fenfluramine (Fig. 4; lower record) produced a similar pattern of negatively-accelerated injections, although the number of injections was reduced.

As noted above, the rate of food-reinforced responding in Food Period II was inversely related to the dose self-delivered in the drug period for both NEA and fenfluramine. Clear instances of strong rate-decreasing effects of NEA (Fig. 3; bottom) and fenfluramine (Fig. 4; bottom) are given, and it should be noted that fenfluramine appeared to exert its greatest rate-decreasing effects $15-30 \mathrm{~min}$ into Food Period II (not seen in the other monkey). 

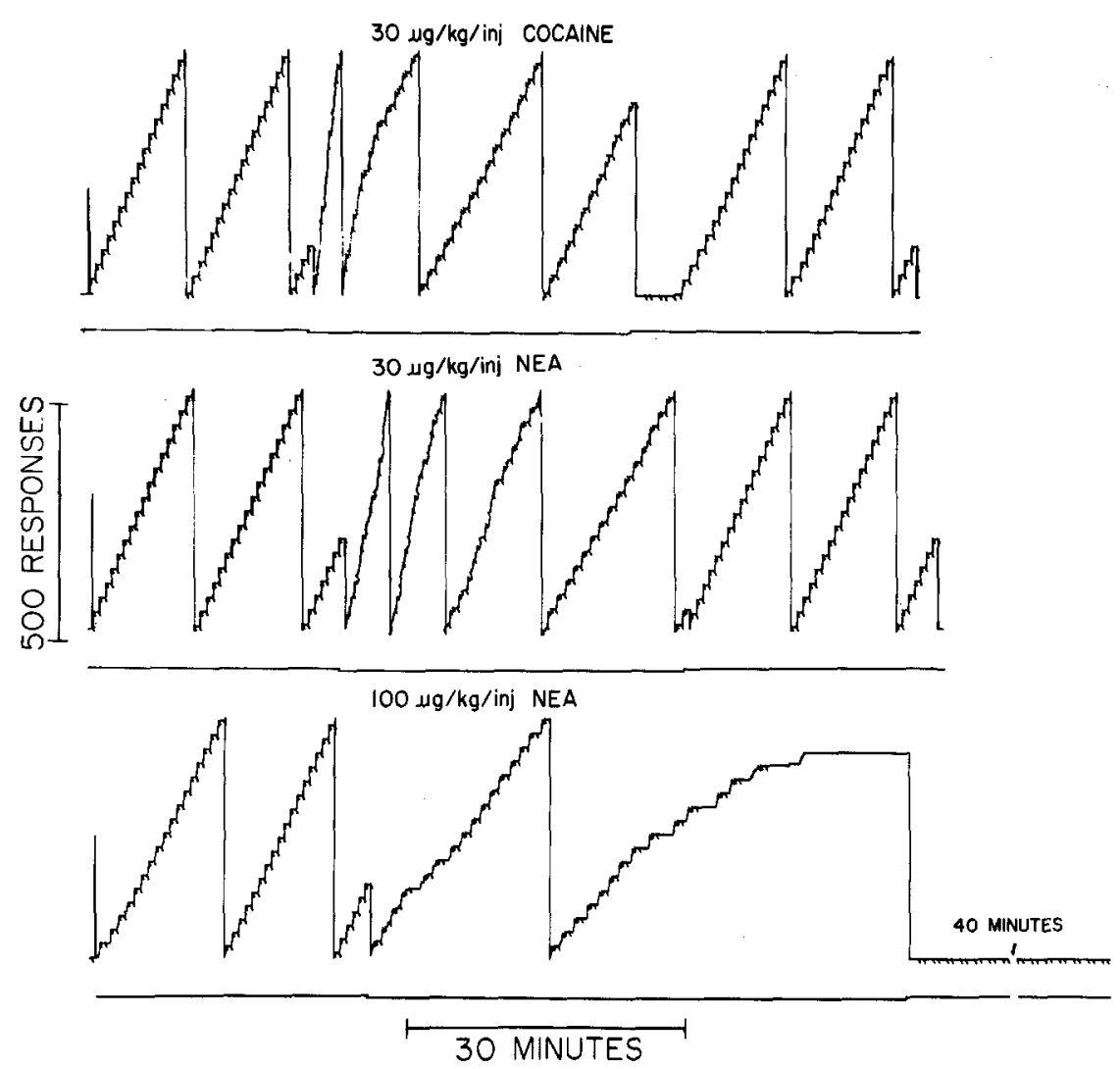

Fig. 3. Cumulative records of performance from a single monkey ( \# 481) in individual sessions involving cocaine $\mathrm{HCl}(30 \mu \mathrm{g} / \mathrm{kg} /$ injection) and doses of $\mathrm{N}$-ethyl amphetamine $\mathrm{HCl}$ (NEA). Each lever-press response moved the top (response) pen in each record upwards one step while the paper advanced from left to right at a constant speed. The response pen reset automatically after approximately 510 responses. When the bottom (event) pen was up, thirty lever-press responses in the presence of a red light resulted in delivery of a $300-\mathrm{mg}$ food pellet. When the event pen was deflected downward, thirty lever presses in the presence of a white light resulted in the delivery of a 15-sec i.v. injection. A green-light period followed food presentation, as well as failure to complete the food-associated response requirement within $1 \mathrm{~min}$, and injection. Downward strokes of the response pen denote changes in light condition. The response pen was also deflected by, and remained deflected during, injection. Periods during which no responding occurred have been removed from the bottom record; the location and duration of the omission have been noted on the record

Further, it should be noted that cocaine (Fig. 3; top record) induced a short-lasting pause at the beginning of the second food period, and subsequently food-reinforced rates of responding appeared at their normal rate. Similarly rapid transitions from druginduced pausing to rapid, sustained responding have been observed following non-response-contingent intravenous cocaine injections in both the rhesus monkey (Woods and Tessel, 1974) and the rat (Pickens and Thompson, 1968).

Fast transition to typical high rates of food-reinforced responding also followed low doses of NEA (not illustrated), low doses of fenfluramine (Fig. 4; middle record), and saline (Fig. 4; top record).

\section{Discussion}

During the drug period, NEA ( $30 \mu \mathrm{g} / \mathrm{kg} /$ injection) maintained responding at a rate significantly higher than that associated with saline, while fenfluramine from 10 through $300 \mu \mathrm{g} / \mathrm{kg} /$ injection did not. These findings show that fenfluramine lacks a positive reinforcing capacity in this situation. These observations on fenfluramine confirm and extend previous findings in the rhesus monkey (Woods and Tessel, 1974; Estrada and Carranza, personal communication) and in the rat (Baxter et al., 1973; Götestam and Andersson, 1975). The failure of fenfluramine to act as a reinforcer of drug-taking behavior in the present study is not due to the presence of an ethyl group on fenfluramine's nitrogen but is attributable to the drug's meta- $\mathrm{CF}_{3}$ group. These data, together with those of previous studies (Tessel et al., 1975a, b), indicate the importance of the meta substitution in modulating the effects of NEA and, by analogy, amphetamine.

The failure of fenfluramine to reinforce drug-taking behavior at any dose from 10 through $300 \mu \mathrm{g} / \mathrm{kg} /$ injection could be attributed to the use of an in- 

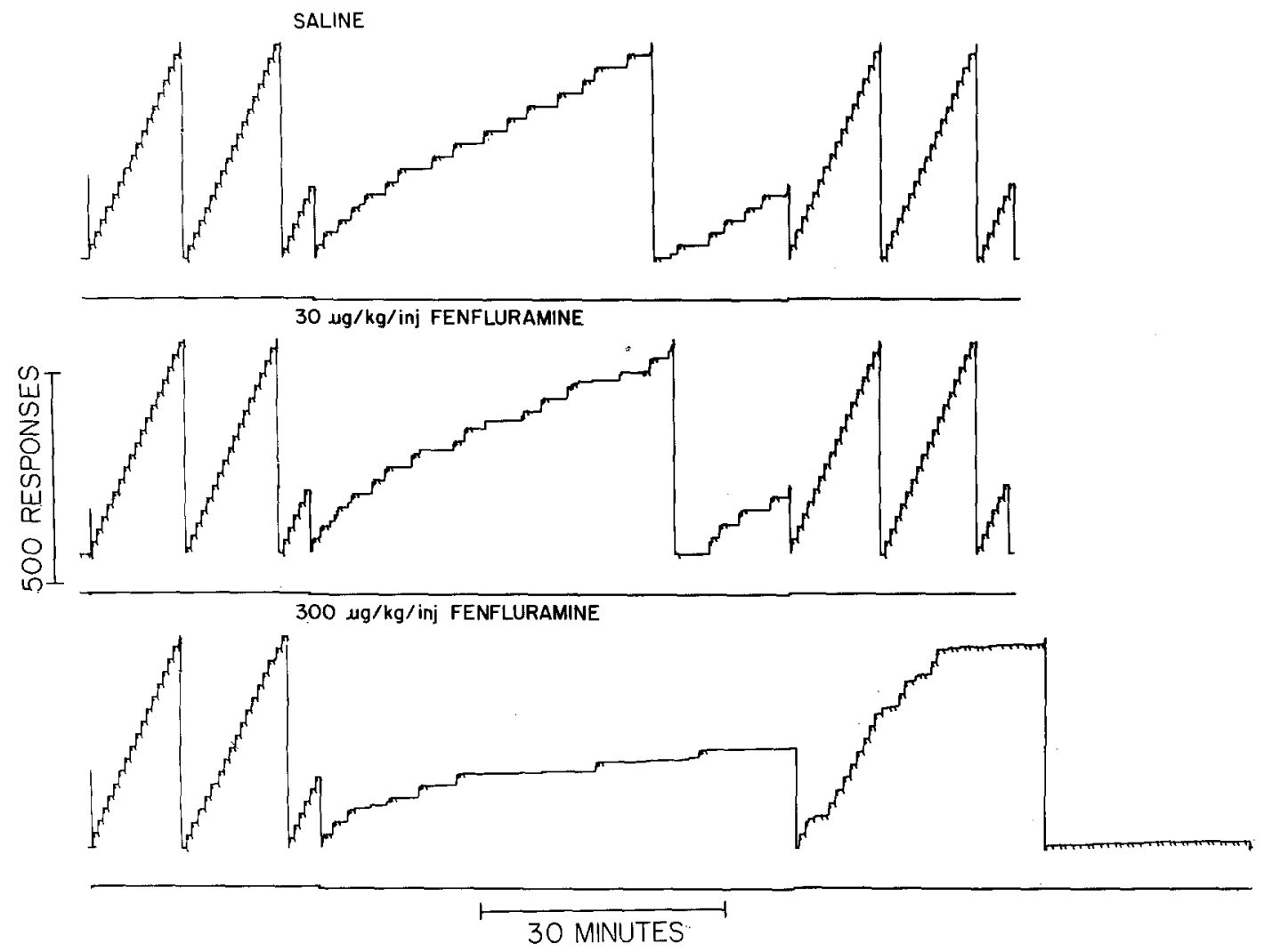

Fig. 4. Cumulative records of performance from a single monkey ( $\# 481$ ) in individual sessions involving saline and two doses of fenfluramine. Conventions of recording are given in the legend of Fig. 3

effective dose range rather than a more general absence of reinforcing efficacy. However, the former possibility is unlikely for several reasons. When a much larger dose range was used in a previous study (3-3000 $\mu \mathrm{g} / \mathrm{kg} /$ injection; Woods and Tessel, 1974), the drug also failed to reinforce self-injection responding. In addition, the use of $300 \mu \mathrm{g} / \mathrm{kg} /$ injection in the present study resulted in a marked reduction in the average response rate in the second food period. Consequently, and by analogy to the data of the present study concerning NEA, it is probable that large doses of fenfluramine would not have manifested rate-enhancing (i.e., reinforcing) actions during the drug period. Due to the concomitant production of rate-disrupting effects by such doses, the resulting response rate would have been little changed or even reduced. It is also unlikely that doses smaller than $10 \mu \mathrm{g} / \mathrm{kg} /$ injection would have been reinforcing since such a finding would indicate that fenfluramine was a more potent agent than NEA. However, fenfluramine has typically been found in other preparations to be less potent than NEA (e.g., Tessel et al., 1975a,b). It appears that fenfluramine and NEA are approximately equivalent in potency in suppressing the second food period when a correction for the drug intake is made (see highest unit doses; Fig. 2; bottom, Fig. 1).

Many psychomotor stimulants have been demonstrated to reinforce self-injection responding (e.g., cocaine, amphetamine, phenmetrazine, pipradol and methylphenidate) in both rats and monkeys (e.g., Downs and Woods, 1974; Goldberg, 1973; Wilson et al., 1971; Yokel and Pickens, 1973). In such studies, as in the present one, intra-session rates of drug-reinforced responding are often uneven with responding being more rapid early in the session and depressed later in the session (i.e., negatively accelerated). Lowering or raising the dose from that which induces maximal rates results in both a more pronounced negative acceleration and a decrease in average rates of responding. These changes in response rate have been attributed to "satiation" (Goldberg, 1973), "autotitration" (i.e. adjustment of response rate to maintain a constant blood level of drug; Yokel and Pickens, 1973, 1974), or "nonspecific behavioral toxicity" (Balster and Schuster, 1973). In addition, as Wilson et al. (1971) have indicated, such changes are also consistent with the dose-related production of aversive effects. 
The data of the present study have import for these several hypotheses. Maximal response rates maintained by NEA during the drug periods were produced by a dose of $30 \mu \mathrm{k} / \mathrm{kg} /$ injection. Increasing the dose to $100 \mu \mathrm{g} / \mathrm{kg} /$ injection resulted in a marked decrease in the average rate of NEA-maintained responding due to a decrease in response rate towards the end of the drug periods. This increased negative acceleration was associated with a decrease in the average rate of responding during the periods of food-reinforced responding which immediately followed. Since both NEA- and food-reinforced responding were markedly decreased contiguously in time, these data suggest that the response-disrupting actions of NEA are not specific to drug-taking but are attributable to some mechanism that affects food-maintained responding as well. Clearly, a pattern of negativelyaccelerated drug-reinforced responding is by itself not sufficient to invoke a process that would be event specific. Similar rates and patterns of responding in the drug period were observed with both high and low doses of NEA, saline and all doses of fenfluramine, yet only high doses of fenfluramine and NEA produced rate-decreasing effects in the second food period.

\section{References}

Adkins, D. C. : Statistics. Columbus: Merrill Books 1964

Babulova, A., Cotillo, P., Bonaccorsi, A., Podvalova, I. Effects of fenfluramine on the adrenergic system. J. Pharm. Pharmacol. 24, 886-893 (1972)

Balster, R. L., Schuster, C. R.: A comparison of $d$-amphetamine, $l$-amphetamine, and methamphetamine self-administration in rhesus monkeys. Pharmacol., Biochem. and Behav. 1, $71-76$ (1973)

Baxter, B. L., Gluckman, M. I., Scerni, R.: Differential selfinjection behavior produced by fenfluramine versus other appetite inhibiting drugs. Fed. Proc. 32, 754 (1973)

Bizzi, A., Bonaccorsi,A., Jespersen, S., Jori, A., Garattini,S. : Pharmacological studies on amphetamine and fenfluramine. In: Amphetamines and related compounds, E. Costa and S. Garattini, eds., pp. 577-596. New York: Raven Press 1970
Deneau, G., Yanagita, T., Seevers, M. H.: Self-administration of psychoactive substances by the monkey. Psychopharmacologia (Berl.) 16, 30-48 (1969)

Le Douarec, J. C., Neveu, C.: Pharmacology and biochemistry of fenfluramine. In: Amphetamines and related compounds, E. Costa and S. Garattini, eds., pp. 75-105. New York: Raven Press 1970

Downs, D. A., Woods, J. H.: Codeine- and cocaine-reinforced responding in rhesus monkeys: effects of dose on response rates under a fixed-ratio schedule. J. Pharmacol. exp. Ther. 191, 179-188 (1974)

Goldberg, S. R.: Comparable behavior maintained under fixed-ratio and second-order schedules of food presentation, cocaine injection or $d$-amphetamine injection in the squirrel monkey. J. Pharmacol. exp. Ther, 186, 18-30 (1973)

Götestam, K. G., Andersson, B. E.: Self-administration of amphetamine analogues in rats. Pharmacol., Biochem. and Behav. (in press, 1975)

Pickens, R., Thompson, T.: Cocaine-reinforced behavior in rats: Effects of reinforcement magnitude and fixed-ratio size. J. Pharmacol. exp. Ther. 161, 122-129 (1968)

Tessel, R. E., Woods, J. H., Counsell, R. E., Basmadjian, G. P. : Structure-activity relationships between meta-substituted $\mathrm{N}$-ethyl amphetamines and isolated guinea-pig atrial rate. J. Pharmacol. exp. Ther. 192, 319-326(1975a)

Tessel, R. E., Woods, J. H., Counsell, R. E., Lu, M.: Structure-activity relationships between meta-substituted $\mathrm{N}$ ethyl amphetamines and locomotor activity in mice. J. Pharmacol. exp. Ther. 192, 310-318 (1975b)

Wilson, M. C., Hitomi, M., Schuster, C. R.: Psychomotorstimulant self-administration as a function of dosage per injection in the rhesus monkey. Psychopharmacologia (Berl.) 22, 271-281 (1971)

Woods, J. H., Tessel, R. E. : Fenfluramine: amphetamine congener that fails to maintain drug-taking behavior in the rhesus monkey. Science 185, $1067-1069$ (1974)

Woodward, E.: Clinical experience with fenfluramine in the United States. In: Amphetamines and related compounds, E. Costa and S. Garattini, eds., pp. 685-691. New York: Raven Press 1970

Yokel, R. A., Pickens, R. : Self-administration of optical isomers of amphetamine and methyl amphetamine by rats. J. Pharmacol. exp. Ther. 187, 27-33 (1973)

Yokel, R. A., Pickens, R.: Drug level of $d$-and $l$-amphetamine during intravenous self-administration. Psychopharmacologia (Berl.) 34, 255-264 (1974)

Ziance, R. J., Sipes, I. G., Kinnard, W. J., Buckley, J. P.: Central nervous system effects of fenfluramine hydrochloride. J. Pharmacol. exp. Ther. 180, 110-117 (1972)

Dr. James H. Woods

The University of Michigan Medical School, Department of Pharmacology

M6322 Medical Science Building, Ann Arbor, Mi. 48104, U.S.A. 